\title{
TELHADO VERDE: ALTERNATIVA SUSTENTÁVEL PARA A DRENAGEM DO ESCOAMENTO SUPERFICIAL
}

\author{
GREEN ROOF: SUSTAINABLE ALTERNATIVE FOR SURFACE FLOW
}

\author{
ETHEL GERALDO CANABRAVA NETO | UFMS \\ ALESKA KAUFMANN ALMEIDA, M.Sc.|UFMS \\ IZABEL RODRIGUES LEITE, M.SC. | UFMS \\ JOSÉ ANTONIO GUARIENTI | UFMS \\ ISABEL KAUFMANN DE ALMEIDA, Dra. | UFMS
}

\begin{abstract}
RESUMO
A drenagem urbana sustentável é técnica que visa manter as paisagens naturais e diminuir as áreas impermeáveis, como ocorre quando da implantação do telhado verde. O telhado verde é uma alternativa a ser considerada para os grandes centros urbanos, consistindo na cobertura vegetal de uma edificação, seja sobre laje ou telhado convencional. Neste trabalho foram investigados aspectos e fatores que podem afetar a qualidade do armazenamento do escoamento superficial do telhado verde, bem como sua contribuição ambiental e econômica. Assim, foram analisadas características externas, como clima e estações do ano, e características internas, relacionadas à estrutura física do telhado. Também foram averiguadas as políticas públicas de incentivo à implementação desse tipo de cobertura. O telhado verde contribui para a gestão da drenagem urbana, auxiliando na captação das águas pluviais, podendo melhorar a qualidade do ar e da água e diminuir a sobrecarga do escoamento.
\end{abstract}

PALAVRAS CHAVE: Águas pluviais; Drenagem Sustentável; Redução do escoamento; Inundação; LID.

\begin{abstract}
Sustainable urban drainage is a technique that aims to maintain natural landscapes and reduce impermeable areas, such as when the green roof is implanted. Green roof is an alternative to consider for large urban centers, consisting of the vegetation cover of a building, either on slab or conventional roof. In this work we investigated aspects and factors that may affect the quality of the green roof surface runoff storage, as well as its environmental and economic contribution. Thus, external characteristics such as weather and seasons, and internal characteristics related to the physical structure of the roof were analyzed. Public policies that encourage the implementation of this type of coverage were also investigated. The green roof contributes to urban drainage management, assisting in the capture of rainwater and can improve air and water quality and reduce runoff overload.
\end{abstract}

KEY WORDS: Rainwater; Sustainable Drainage; Reduction of flow; Flood; LID. 


\section{INTRODUÇÃO}

A relação entre o ambiente construído e o natural deve ser concebida integrando as características da vida e do clima locais, visando o conforto e a sustentabilidade ambiental. Ambos os ecossistemas, terrestres e aquáticos são, drasticamente, e muitas vezes irrevogavelmente, alterados durante o processo de urbanização (PICKET et al., 2001; PAUL e MEYER, 2001). Segundo Costanza et al. (1997), os principais serviços ecossistêmicos eliminados ou consideravelmente desgastados são: regulação e suprimento de água, controle de erosão e retenção de sedimentos, ciclagem de nutrientes, regulação do clima e mudanças no tratamento de resíduos. Os desastres ocorrem pelas superfícies impermeáveis e pela construção de estruturas feitas pelo homem em áreas altamente desenvolvidas que estão por trás do decaimento ambiental (ARNOLD e GIBBONS, 1996). Segundo Mentens, Raes e Hermy (2006) a urbanização contínua envolve o uso insustentável de sistemas naturais e gera numerosos problemas dentro e fora das cidades. Amplas áreas impermeabilizadas são criadas, seja por meio da pavimentação das cidades, seja pela diminuição da vegetação, refletindo na formação de um efeito conhecido como ilha de calor urbano, no qual há acréscimo na temperatura local como resultado da substituição de áreas verdes por concreto, uma vez que estes retêm maior calor que a vegetação (OKE, 1987). Para White (2002), há redução de infiltração da água no solo, sobrecarregando a rede de drenagem, principalmente durante os períodos de chuva, quando o escoamento superficial é extremamente alto.

A aplicação de técnicas de desenvolvimento de baixo impacto (Low Impact Development - LID) é uma alternativa para minimizar os efeitos da urbanização. Trata-se de técnica de drenagem urbana sustentável que visa manter paisagens naturais e reduzir áreas impermeáveis como, por exemplo, biorretenção de água ou jardins de chuva, utilização de pavimentos permeáveis ou implantação de telhado verde (DIETZ, 2007). Segundo Ferguson (1998), para minimizar o escoamento superficial ocasionado pelas chuvas, ferramentas que aumentam a retenção de água, como reservatórios de armazenamento e tanques, onde a água pode ser acomodada temporariamente, e áreas verdes, onde a água pode infiltrar e evaporar, são as melhores alternativas. Para minimizar os problemas causados pela pavimentação impermeável das cidades, deve-se implantar áreas verdes. No entanto, o alto custo dos terrenos torna economicamente inviável, ou até mesmo impossível, a criação dessas áreas. Ademais, no ambiente urbano tem-se elevada quantidade de área de cobertura das edificações não utilizada. Nesse contexto, Dunnett e Kingsbury (2004) afirmam que os telhados verdes ou jardim suspensos são a alternativa mais exequível na busca de uma urbanização ecológica.

O telhado verde, também conhecido como cobertura verde, telhado vivo ou jardim suspenso, tem se mostrado uma alternativa sustentável e viável nos grandes centros urbanos. Esse sistema consiste na cobertura vegetal da edificação, sobre a laje ou telhado convencional. Quando sobre este, proporciona a proteção da radiação ultravioleta (UV) e das temperaturas extremas, as duas principais fontes de degradação dos telhados comuns (THOMPSON e SORVIG, 2008). Segundo Oberndorfer et al. (2007) essa técnica é dividida basicamente em duas: os telhados verdes intensivos que detêm aparência de jardins convencionais ao nível do solo e possuem um investimento em manutenção considerável e os telhados verdes extensivos que, basicamente, possuem substratos mais rasos, como gramíneas, e exigem menos manutenção. A implantação do telhado verde implica na melhoria da qualidade do ar e redução das ilhas de calor (GAFFIN et al., 2006), no controle do escoamento superficial (YANG, YU, e GONG, 2008) e no conforto térmico e acústico (VECCHIA, 2005).

Neste trabalho foram investigados aspectos e fatores que podem afetar a qualidade do armazenamento do escoamento superficial do telhado verde, bem como sua contribuição ambiental e econômica. Assim, foram analisadas características externas, como clima e estações do ano, e características internas, relacionadas à estrutura física do telhado. Também foram averiguadas as políticas públicas de incentivo à implementação desse tipo de cobertura.

\section{DRENAGEM URBANA}

O crescimento significativo da população urbana nas últimas décadas é sentido principalmente na área de gestão das águas urbanas, a qual envolve principalmente os sistemas relativos a redes de água, esgoto e drenagem. A alteração do sistema natural decorrente da urbanização altera o comportamento hídrico da bacia hidrográfica. $\mathrm{O}$ aumento de áreas impermeabilizadas em centros urbanos causa, dentre outros fatores, o aumento da temperatura, a diminuição do tempo de concentração e o aumento da vazão de pico do escoamento superficial. A água precipitada escoa por telhados e pavimentos impermeáveis até chegar ao coletores e condutos que a levarão à jusante. Essas superfícies impermeáveis inviabilizam a infiltração da água no solo, fazendo com que a mesma chegue com maior velocidade à jusante, provocando inundações. 
O crescimento urbano e o consequente aumento de áreas impermeabilizadas torna o gerenciamento da drenagem urbana um desafio importante. Entender como administrar adequadamente as águas pluviais urbanas é uma preocupação crítica para engenheiros civis e ambientais em todo o mundo. A má gestão das águas pluviais e do escoamento urbano resulta em problemas de inundação, erosão e qualidade da água. Os sistemas de drenagem tradicionais são geralmente redes de esgotos que transportam águas residuais urbanas e águas pluviais para um ou mais pontos terminais, onde são tratadas e /ou descarregadas no meio ambiente (CEMBRANO et al., 2004). Esse material é captado e levado por condutos artificiais, geralmente subterrâneos, sempre do maior aclive para o menor, sendo retirados das áreas urbanas e lançados em corpos de água, contribuindo assim para a degradação da qualidade de águas dos rios, gerando condição desconforto ambiental.

Os sistemas comumente utilizados de drenagem são o unitário e separador absoluto. O sistema unitário, também denominado combinado ou romano consiste em rede de coleta e condução de esgoto doméstico, despejo industrial e água pluvial. Em regiões de clima tropical, como o Brasil, nas quais as estações chuvosas e secas são bem definidas, evidenciam-se as desvantagens desse sistema quanto ao dimensionamento, devido à grande variação sazonal de vazões. No período de estiagem os condutos são subutilizados devido à baixa vazão do componente esgoto pluvial. Já nos períodos chuvosos, um volume elevado é conduzido às estações de tratamento, havendo o risco de rompimento da rede quando ocorrem chuvas de alta intensidade. No sistema separador absoluto, as águas pluviais são coletadas e transportadas por um sistema totalmente independente e não recebem tratamento antes de serem lançadas nos cursos d'água. Nesse sistema, a rede de esgoto é projetada para transportar exclusivamente despejos industriais e esgoto doméstico, apresentando vazão constante ao longo do ano.

Segundo Willems et al. (2012) os sistemas de esgoto, devido ao aquecimento global, estão se tornando cada vez mais vulneráveis a extremos de chuvas, aumentando assim os riscos de sobrecarga. Conforme Cembrano et al. (2004), em cidades onde a urbanização está crescendo rapidamente e a incidência de chuvas intensas são comuns, os sistemas de esgoto combinados existentes são incapazes de transportar todo o escoamento superficial para as estações de tratamento.

A gestão das ações relacionadas ao corpos hídricos nas áreas urbanas são realizadas tendo como base a unidade bacia hidrográfica. As bacias hidrográficas possuem como gestores comitês e agências que utilizam os planos de bacia como instrumentos de gestão. Os planos de bacia hidrográficas envolvem questões relacionadas, principalmente, à quantidade e à qualidade da água dos rios da bacia, com o objetivo de não transferir impactos. No entanto, um fator importante, que interfere no escoamento e na ocorrência de inundações, é a gestão do uso do solo, a qual é realizada pelo município, ou, no caso de regiões metropolitanas, por um grupo de municípios. Os instrumentos utilizados pelos municípios para gestão das águas urbanas consistem no plano diretor urbano e plano integrado de esgotamento, drenagem urbana e resíduo sólido. Conforme Tucci (2008) esses instrumentos usados pelos municípios têm como características minimizar os impactos dentro das cidades, nas pequenas bacias urbanas, e não transferir os impactos para o sistema de rios.

No Brasil e em outros países com infraestrutura precária, tem-se o agravante do conceito higienista ser mal aplicado, seja por falta de recursos, mau dimensionamento, má execução ou por manutenção ineficiente. O princípio dos projetos de drenagem são baseados em retirar rapidamente a água pluvial excedente de seu local de origem e realizar obras pontuais para mitigar eventuais inundações em regiões críticas. Esse padrão utilizado na concepção de projetos de drenagem acaba apenas transferindo a inundação para outro ponto da bacia hidrográfica. A partir dos anos 1970 surgiu em países da Europa e América do Norte uma nova abordagem para a drenagem, tratam-se das tecnologias alternativas ou compensatórias (BAPTISTA et al., 2015). O conceito ambientalista dessas técnicas tem o intuito de introduzir uma série de práticas de manejo das águas pluviais na tentativa de compensar boa parte das deficiências apresentadas pelos sistemas baseados no conceito higienista (POLETO et al., 2015). Esse tipo de abordagem dado ao tratamento das águas pluviais no meio urbano prioriza a manutenção dos mecanismos naturais de escoamento nas bacias hidrográficas, a despoluição das águas e a preservação das margens naturais dos cursos d'água.

O conceito de cidades sustentáveis resultou de um movimento com o objetivo de tornar as cidades lugares mais verdes e saudáveis para seus habitantes, com sustentabilidade que envolve viabilidade econômica, estabilidade social e uso inteligente de recursos hídricos, protegendo e nutrindo o ambiente natural (LEITMANN, 1999). Com a alta urbanização das grandes cidades, práticas sustentáveis em nossos meios diários são indispensáveis como, por exemplo: ciclovias como uma alternativa ao transporte, investimento em transporte público para diminuir os 
problemas de engarrafamento no trânsito, racionamento de consumo de água, técnicas de uso da radiação solar para aquecimento de água nas residências, reuso de água da chuva, sistemas de drenagem sustentáveis (SUDS) para diminuir os problemas de drenagem urbana, entre outros.

Sistemas de drenagem urbana precisam ser planejados de forma integrada com o crescimento urbano e as soluções de drenagem devem ser integradas com a paisagem urbana (MIGUEZ, MASCARENHAS e MAGALHÃES, 2007). Os SUDS vieram para minimizar os problemas de contaminação de água das cidades devido à expansão das mesmas, da mudança do estilo de vida da população e dos problemas oriundos do aumento do escoamento superficial de água (JONES e MACDONALD, 2007). A drenagem sustentável tenta reproduzir os processos decorrentes da impermeabilização do solo e do desmatamento, fazendo com que a água infiltre no solo ou seja armazenada temporariamente, através de novas estruturas de drenagem chamadas de não convencionais.

Segundo Charlesworth et al. (2003), SUDS é um termo genérico para vários sistemas diferentes, que diminuem e retêm o escoamento, favorecendo a drenagem superficial. A pavimentação porosa, por exemplo, cria vazios no qual o material escoado pode atravessar a superfície e ser infiltrado no solo, diminuindo o produto final do escoamento desembocado no rio, ao contrário de um acabamento impermeabilizante (JONES e MACDONALD, 2007). Segundo Ellis et al. (2004) o uso de elementos orgânicos como gramíneas e, em particular, os canaviais, mostra-se extremamente eficiente na remoção da poluição de fontes difusas lavadas de superfícies urbanas. O SUDS tem, assim, três grandes benefícios do ponto de vista da drenagem, que são eles: reduzir a carga geral nos drenos convencionais, reter os fluxos de pico para evitar a sobrecarga e remover a poluição da fonte difusa para limpar as descargas. O SUDS também pode trazer benefícios secundários de natureza estética e ecológica, particularmente quando são utilizados lagos e zonas úmidas (JONES e MACDONALD, 2007). Um exemplo de SUDS são os telhados verdes. De acordo com Oberndorfer et al. (2007), os telhados verdes são ideais para o gerenciamento de águas pluviais urbanas.

\section{TELHADO VERDE}

O telhado de uma edificação pode ser totalmente ou parcialmente coberto por camada de vegetação. Telhado verde é um sistema em camadas que compreende uma membrana impermeabilizante, uma camada de solo e a própria camada de vegetação. Conforme Castleton et al.
(2010), os telhados verdes, muitas vezes, também incluem uma camada de barreira de raízes, uma camada de drenagem e, onde o clima exige, um sistema de irrigação.

Os jardins de telhado que são os antecessores dos jardins suspensos atuais, têm origens antigas. Segundo Oberndorfer et al. (2007) os jardins suspensos de Semiramis ou jardins Suspensos da Babilônia, localizados na Síria, foram os primeiros jardins de telhado documentado. Nos dias atuais, esse tipo de cobertura é usado de forma similar em projetos de hotéis internacionais de alto perfil, centro de negócios e edificações residenciais. Países como Áustria, Alemanha, Suíça, Estados Unidos, Bélgica, Noruega, Hungria, Suécia, Reino Unido, Itália, Singapura, Coréia do Sul, Austrália, Japão, China, Hong Kong, Canadá e Dinamarca (entre outros) aplicam a tecnologia de telhado verdes em suas construções baseando-se em regulamentos legais e recomendações visando, dentre outros benefícios, a gestão de águas pluviais (DA COSTA RANGEL et al., 2015; GARRIDO NETO, 2016; SHAFIQUE, KIM e RAFIQ, 2018). De acordo com Shafique, Kim e Rafiq (2018), na Alemanha, mais de $10 \%$ dos edifícios usam práticas de telhados verdes para vários benefícios. Os telhados verdes, além de adicionarem benefícios estéticos às edificações, são usados com a finalidade de diminuir o volume do escoamento, melhorar a qualidade do ar e da água e promover a conservação de energia. Os telhados verdes apresentam vantagens econômicas e ecológicas adicionais, como mitigação da ilha de calor urbana, gerenciamento de águas pluviais, sequestro de carbono, redução do ruído e poluição do ar, proporcionando espaço para a produção de alimentos urbanos, fornecendo habitat para a vida selvagem e melhorando a saúde humana (EKSI et al. 2017; GETTER et al., 2009; OBERNDORFER et al., 2007; ROWE, 2011; WHITTINGHILL e ROWE, 2012). A redução no escoamento superficial geralmente varia de $50 \%$ a $100 \%$, dependendo do tipo de sistema de telhado verde, composição e profundidade do substrato, declividade do teIhado, espécies de plantas, umidade do substrato preexistente e intensidade e duração da chuva (ROWE, 2011).

\subsection{Contribuição ambiental e econômica}

O avanço da urbanização e a alteração da pavimentação, de permeável para impermeável, desencadeou problemas ambientais que, cada vez mais, refletem na vida da população contemporânea. Segundo Tsang e Jim (2011), os telhados verdes oferecem uma maneira natural e sustentável de cobrir edificações com vegetação, trazendo múltiplos benefícios ambientais. 
O telhado convencional exposto possui uma membrana que absorve a radiação solar, retendo essa radiação e fazendo com o que a temperatura interna aumente durante o dia. No período da noite a temperatura superficial do telhado diminui. Essa oscilação de temperatura diminui a vida útil da estrutura em decorrência das tensões térmicas criadas na membrana e traz desconforto térmico para os moradores. O telhado verde impede que a radiação solar atinja a membrana, visto que a vegetação absorve essa radiação, fazendo com que diminuam as flutuações de temperatura, possibilitando que o telhado verde dure praticamente o dobro do tradicional (TEEMUSK e MANDER, 2009). Conforme Oke (1987), outro benefício propiciado pela absorção da radiação solar nos telhados verdes é a redução dos efeitos urbanos das ilhas de calor por meio da evapotranspiração.

Os telhados verdes contribuem com a economia de energia destinada à refrigeração e aquecimento de ambientes aonde é empregado. De acordo com Santamouris et al. (2007) a cidade de Atenas, Grécia, é caracterizada por forte efeito ilha de calor, que ocorre no verão e no inverno, com intensidade diária média variando entre 6 e $12^{\circ} \mathrm{C}$. Conforme estudo desenvolvido pelos mesmos autores, houve economia de energia durante o verão, a redução variou de $15-49 \%$ para construção não isolada, e de $6 \%$ a $33 \%$ para construção isolada. De acordo com Niachou et al. (2001) as cargas estimadas de aquecimento e refrigeração são menores no edifício com o telhado verde, independentemente do tipo de isolamento do telhado. DeNardo et al. (2005), em estudo realizado no estado da Pensilvânia, Estados Unidos da América, concluíram que as temperaturas máximas da superfície do telhado verde estiveram em média $6^{\circ} \mathrm{C}$ mais altas no inverno e $19^{\circ}$ $C$ mais baixas no verão. Os autores verificaram, ainda, que as diferenças entre a mudança da temperatura máxima diurna na superfície do telhado tiveram variação média de $19^{\circ} \mathrm{C}$ de agosto a setembro (meses com elevado uso de aparelhos de refrigeração devido as altas temperaturas) e de $8{ }^{\circ} \mathrm{C}$ de outubro a fevereiro (meses com elevado uso de aquecedores devido às baixas temperaturas).

Eksi et al. (2017) em seu estudo realizado em região de clima temperado na cidade de East Lansing (EUA), compararam duas estruturas de telhado verde e verificaram seu desempenho nas quatro estações climáticas do ano. A primeira estrutura com profundidade de $5 \mathrm{~cm}$ e a segunda com profundidade de $20 \mathrm{~cm}$ contendo 17 espécies de herbáceas perenes e gramíneas. De acordo com os autores, o telhado mais raso apresentou ser mais vantajoso durante o verão, e o telhado espesso reduziu a perda de calor do edifício, sendo mais vantajoso durante o inverno.
O telhado verde e seus benefícios térmicos são essenciais para o projeto de arquitetura em região de clima tropical, clima predominante no território brasileiro, por ser considerado um potencial meio de resfriamento passivo. Em estudo realizado em Cingapura, Wong et al. (2003) detectaram que a temperatura máxima da superfície de edificações em laje pode atingir $57^{\circ} \mathrm{C}$ durante o período vespertino, quando a radiação solar está em torno de $1400 \mathrm{~W} / \mathrm{m}^{2}$. Os autores constataram que, com a implementação de telhado verde, principalmente devido ao sombreamento gerado pelas plantas, as temperaturas superficiais máximas medidas sob diferentes tipos de vegetação diminuíram em torno de $30^{\circ} \mathrm{C}$ em comparação à superfície em laje.

Os telhados verdes também são ótimos mecanismos que auxiliam no gerenciamento de águas pluviais. Técnicas convencionais de gerenciamento de águas pluviais incluem reservatórios e tanques de armazenamento, áreas úmidas construídas e filtros de areia; no entanto, essas tecnologias intensivas de área superficial podem ser difíceis de implementar em centros urbanos densos (MENTENS, RAES E HERMY, 2006). Os telhados verdes são indispensáveis para esse tipo de gerenciamento, já que eles ocupam espaços que não estão sendo usados nos centros urbanos e ajudam a evitar o escoamento de forma local. Segundo Köhler et al. (2002), telhados verdes podem reduzir o escoamento total anual em até $60 \%$ a 79\%. Mentens, Raes e Hermy (2006) constataram, através de simulação feita em apenas $10 \%$ de todos os telhados de região urbanizada de Bruxelas, a redução do escoamento regional em 2,7\%. DeNardo et al. (2005) avaliaram sete eventos de chuva de altura média de $19,7 \mathrm{~mm}$ e intensidade média máxima de $4,3 \mathrm{mmh}^{-1}$, e verificaram que, nos telhados verdes, essa chuva foi retida, em média, $45 \%$ (variação de 19\% a 98\%) e o tempo de pico do escoamento foi atrasado em $2 \mathrm{~h}$.

Telhados verdes também proporcionam benefícios estéticos e psicológicos para pessoas em áreas urbanas (OBERNDORFER et al., 2007). Isso os torna um sistema eficiente, já que recuperam espaços sem cor e sem vida, deixando-os habitáveis, ampliando a área útil do imóvel e, por fim, agregando valor em possível venda no futuro. Outros usos para os telhados verdes incluem a agricultura urbana, que consiste na produção de alimentos, proporcionando benefícios econômicos e educacionais para os moradores (OBERNDORFER et al., 2007). Para Dunnett e Kingsbury (2004), os telhados verdes também são ótimos isolantes acústicos, absorvendo as ondas sonoras fora dos edifícios e impedindo a transmissão interna. 


\subsection{Estrutura e tipos de telhados verdes}

Para a implantação do telhado verde, deve-se primeiramente analisar o tipo de estrutura da cobertura na qual o mesmo será instalado. Quando a cobertura for basicamente constituída pela laje, com ou sem inclinação, é necessário que a superfície seja simplesmente impermeabilizada. Se for moldado sobre telhado constituído de telha cerâmica, é preciso retirá-las e colocar placas de madeira compensada que servirão de base para a cobertura vegetal. Segundo Dhalla e Zimmer (2010), os telhados verdes são compostos por múltiplas camadas (Figura 1) que incluem: camada impermeabilizante que protege a superfície impermeável, pode ser de origem betuminosa ou sintética; camada drenante que serve para drenar a água da chuva e para separar os poluentes, constituída de brita, seixos ou argila expandida; camada filtrante que retém partículas que seriam levadas pelo escoamento superficial; solo e substrato que fazem parte da base do plantio da vegetação e, como última etapa, a vegetação, cuja escolha depende do quanto de carga a estrutura suporta, do tipo do telhado verde que foi escolhido e do clima do local.

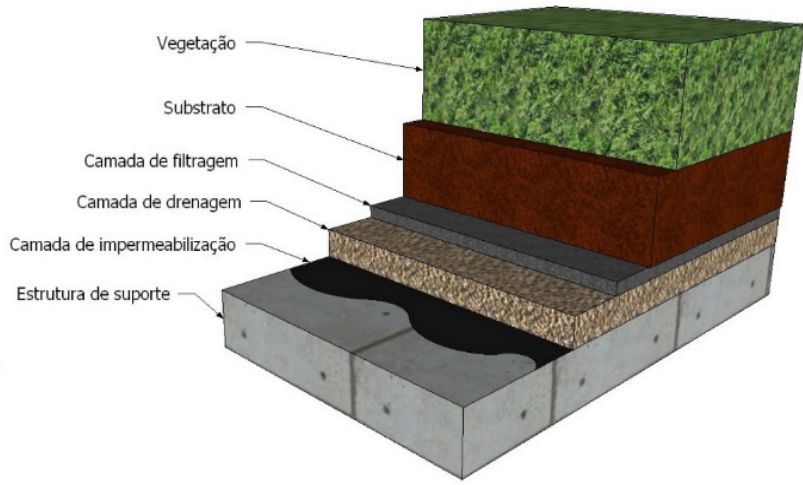

Figura 1: Camadas de um telhado verde básico Fonte: Autores

O tipo de telhado depende do sistema construtivo escoIhido para o telhado convencional e o objetivo a ser alcançado. Segundo Krupka (1992) os telhados verdes são divididos em dois tipos, os telhados intensivos e os extensivos.

Os telhados verdes intensivos possuem aparência de um jardim convencional ao nível do solo e sustentam plantas maiores, como árvores e arbustos. São compostos de substrato mais profundo e podem aumentar o espaço de vida e recreação em áreas urbanas densamente povoadas. Segundo Berndtsson, Bengtsson, e Jinno (2009), esse tipo de telhado requer manutenção como capina, adubação e irrigação. Para Mentens, Raes e Hermy (2006), os telhados verdes intensivos possuem substrato superior a $150 \mathrm{~mm}$ e normalmente são instalados com inclinação inferior a $10^{\circ}$ e, dependendo do projeto e da acessibilidade, podem ser usados como jardins de cobertura, hortas ou ainda plantio de árvores frutíferas de pequeno porte.

Os telhados verdes extensivos possuem camada de substrato mais fina chegando no máximo a $150 \mathrm{~mm}$ de espessura. Geralmente são compostos por gramíneas da espécie Sedum que formam a maior parte da vegetação. Como seu método de execução é mais simples, eles podem ser instalados em superfícies com até $45^{\circ}$ de inclinação (MENTENS, RAES e HERMY, 2006). Esses tipos de telhado, que são mais leves e mais simples, são planejados para serem praticamente livres de manutenção (BERNDTSSON, BENGTSSON e JINNO, 2009). Conforme Oberndorfer et al. (2007), o projeto básico de telhado verde extensivo foi implementado e estudado em diversas regiões e climas em todo o mundo.

\subsection{Fatores que afetam a eficiência da conten- ção de água do telhado verde e a dinâmica do escoamento}

Os motivos que influenciam na capacidade de retenção de água do telhado verde, bem como a dinâmica do escoamento, dependem de dois conceitos distintos: as características dos telhados (número de camadas, tipo de materiais, espessura do solo, tipo do substrato, cobertura vegetal e tipo de vegetação, e geometria do telhado) e a condição climática da área de aplicação. Diversos estudos (YANG, YU e GONG, 2008; MENTENS, RAES e HERMY, 2006; VILLARREAL e BENGTSSON, 2005) demonstram que os teIhados verdes influenciam na redução do escoamento de águas pluviais. A dimensão dessa influência depende da espessura do substrato do solo, da dimensão do evento de precipitação ou distribuição de precipitação durante os períodos de estudo, da idade do telhado, da cobertura vegetal e da inclinação da superfície. Segundo Villareal e Bengtsson (2005), a retenção de água pelo telhado verde depende da intensidade da chuva, sendo que, quanto maior a intensidade menor a retenção. Conforme Carter e Rasmussen (2006), para pequenas tempestades, o pico de descarga é consideravelmente menor em telhado verde do que em telhado convencional. No entanto, para tempestades maiores, esse efeito é significativamente reduzido.

Características como idade do telhado, saturação e espessura do substrato, idade da camada permeável e vegetação influenciam na eficiência da retenção do escoamento superficial no telhado. Com relação à umidade do solo usado no substrato, pode-se afirmar que o escoamento do telhado não ocorre até que o solo esteja na 
capacidade de campo (BENGTSSON, GRAHN e OLSSON, 2005). A capacidade de campo corresponde à capacidade de retenção de água no telhado que nada mais é que a diferença entre a capacidade de campo e o ponto de murchamento (água disponível na planta). Em relação à espessura do substrato, o escoamento total é maior em teIhados com substrato mais raso e encostas mais íngremes (MENTENS, RAES e HERMY, 2006). O substrato do telhado verde sofre alterações em sua funcionalidade com relação ao tempo, alterando assim a capacidade do telhado com relação ao escoamento. Getter, Rowe, e Andresen (2007), utilizaram plataformas de telhado com três anos de idade no início do estudo, em que amostras de substrato foram coletadas para quantificar as mudanças de substrato ao longo do tempo. Os autores verificaram que o substrato maduro apresentou maiores valores de porosidade, espaço aéreo livre (macroporos), matéria orgânica e capacidade de retenção de água em relação ao substrato inicial

Estudos sobre a inclinação do telhado verde apresentam resultados adversos. Enquanto que alguns estudos não encontraram nenhuma correlação entre inclinação e escoamento superficial (BENGTSSON, 2005) outros observaram que a retenção do escoamento pluvial pode estar relacionada ao nível das encostas (VANWOERT et al. 2005). Villarreal e Bengtsson (2005), através de experimentos controlados (com condições iniciais seca e úmida) avaliaram respostas de telhados verdes de diferente inclinação a eventos individuais de chuva e concluíram que a inclinação do telhado verde não influenciou a forma do hidrograma de escoamento direto. No entanto, os autores verificaram que as condições iniciais seca ou úmida, afetaram a capacidade de retenção do telhado verde. Vanwoert et al. (2005) investigaram a influência da declividade e profundidade do substrato na retenção de escoamento de telhados com vegetação. Os autores concluíram que, de todas as categorias estudadas ( $2 \%$ - $25 \mathrm{~mm}, 2 \%$ - $40 \mathrm{~mm}$, $6,5 \%-40 \mathrm{~mm}, 6,5 \%-60 \mathrm{~mm}$ ) a maior porcentagem de retenção (87\%) ocorreu no telhado de $2 \%$ de inclinação e $40 \mathrm{~mm}$ de espessura de substrato.

\subsection{Políticas públicas de incentivo}

O aumento da urbanização e os evidentes problemas gerados por este fenômeno fizeram com que medidas de incentivo para atitudes sustentáveis da população fossem tomadas. No caso do escoamento urbano essa proposta se enquadra nas medidas de controle não estruturais que não solucionam o problema da drenagem urbana sozinhos, mas auxiliam a minimizar os prejuízos relacionados à ocorrência de eventos pluviométricos intensos.
No Brasil, a prática de gestão baseada em técnicas compensatórias passou a ser utilizada a partir dos anos de 1990, década em que muitos municípios brasileiros deram início à elaboração de seus Planos Diretores de Drenagem Pluvial e Esgotamento Sanitário (POLETO et al., 2015). De acordo com Poleto et al. (2015) a aplicação dos princípios de técnicas compensatórias no Brasil é, normalmente, imposta por meio de decreto ou lei municipal, que obriga que empreendimentos que se enquadrem em algumas características (área do lote, percentual de área impermeável, localização na bacia) façam uso de um ou mais tipos de técnicas compensatórias.

No Brasil, as medidas de incentivo à aplicação de técnicas compensatórias são pequenas, sendo muitas vezes uma iniciativa de caráter voluntário. Podem ser listadas algumas legislações que contém regulamentações quanto à implementação de telhados verdes: do estado de Santa Catarina, Lei no 14.243 (SANTA CATARINA, 2007), de 11/12/2007; do município de Guarulhos, Lei no 7.031 de 17 de abril de 2012 (GUARULHOS-SP, 2012); do estado do Rio de Janeiro, Lei no 6.349 (RIO DE JANEIRO, 2012), de 30/11/2012; do município de João Pessoa-PB, Lei $n^{\circ}$ 10.047 de 09 de julho de 2013 (JOÃO PESSOA-PB, 2013); do Município de Canoas, Lei no 5.840 (CANOAS-RS, 2014), de 27/05/2014; do município de Recife, Lei no 18.112 (RECIFE$P E, 2015)$, de 12/01/2015; do município de São Paulo, Lei nº 16.277 (SÃO PAULO-SP, 2015), de 05/10/2015.

A Lei no 14.243 do estado de Santa Catarina trata da criação do programa estadual de incentivo a adoção de telhados verdes em espaços urbanos densamente povoados. A Lei n 6.349 do estado do Rio de Janeiro incentiva a construção de telhados verdes em prédios públicos, autarquias e fundações do Estado, projetados a partir da promulgação da referida Lei. A Lei n 7.031, do município de Guarulhos-SP, de 17 de abril de 2012, versa sobre a instalação do telhado verde em locais especificados e, determina que os projetos de construção edificados, residenciais ou não, com mais de 03 (três) unidades agrupadas verticalmente deverão prever a construção do teIhado verde. A mesma determinação sobre construções verticais está presente na legislação do município de João Pessoa-PB. Ainda quanto a Lei no 10.047, a mesma estabelece que a área destinada pelas construções edificadas ao "Telhado Verde" será considerada, para todos os efeitos, como tendo as mesmas características de área permeável. A Lei Municipal de Canoas, assinada em maio de 2014, dispõe sobre as situações de obrigatoriedade e de recomendação de implantação de telhado verde. A referida Lei n 5.840 versa que é obrigatória a instalação do sistema 
de Telhados Verdes aos imóveis que em seu processo de construção, tenham causado danos ao meio ambiente com derrubada de árvores nativas. Ainda sobre a Lei $n^{\circ}$ 5.840, a mesma prevê a instalação de sistema de Telhado Verde com a finalidade de compensar parcialmente a construção sobre Área Livre Obrigatória mínima necessária para o terreno. A Lei Municipal de Recife prevê a implantação de Telhado Verde em edificações habitacionais multifamiliares com mais de quatro pavimentos e não-habitacionais com mais de $400 \mathrm{~m}^{2}$ de área de coberta. Em 5 de outubro de 2015 foi assinada a Lei $n^{\circ} 16.277$ que dispõe sobre a obrigatoriedade da instalação do telhado verde em locais específicos (São Paulo-SP, 2015).

Outro meio de incentivo notável é o chamado IPTU verde. A Lei municipal $n^{\circ} 6.793$ assinada no dia 28 de dezembro de 2010 (GUARULHOS-SP, 2010), dá desconto de até $20 \%$ no valor anual do IPTU no município a partir da adoção de duas ou mais medidas ambientais, dentre elas a instalação de telhado verde. Em 28 de dezembro de 2012 foi instituída a Lei complementar no 235 a qual trata do programa IPTU Verde no município de Goiânia (GOIÂNIA, 2012). O decreto no 29.100 de 06 de novembro de 2017 (SALVADOR-BA, 2017) institui o Programa de Certificação Sustentável "IPTU VERDE" em edificações no Município de Salvador e estabelece benefícios fiscais aos participantes do programa. O decreto n²9.100 classifica as edificações em diferentes categorias, definindo o desconto no IPTU através de pontos atribuídos a ações e práticas sustentáveis adotadas, ou seja, que promovam a redução do consumo de recursos naturais e impactos ambientais. A Lei Complementar n. 9 913, de 21 de dezembro de 2015 (SANTOS-SP, 2015), concede incentivo fiscal à implantação de "coberturas verdes" nos edifícios do município, o incentivo refere-se ao desconto de até $10 \%$ no IPTU de acordo com a porcentagem de cobertura verde em relação à cobertura total do imóvel.

\section{CONSIDERAÇÕES FINAIS}

A implantação de coberturas verdes é incentivada pela legislação como meio de redução de impactos ambientais oriundos da urbanização. Em regiões densamente povoadas, com elevada densidade demográfica, o uso de telhados verdes é incentivado como forma de compensar áreas permeáveis no terreno. As coberturas verdes proporcionam benefícios como: retenção de águas pluviais e redução do escoamento superficial; melhoria da qualidade da água para aproveitamento; conforto térmico e redução dos custos de energia; melhoria da qualidade do ar; redução de ruído; além de benefícios ecológicos, sociais e econômicos.
O telhado verde é excelente estrutura que contribui para a gestão da drenagem urbana, auxiliando na captação das águas pluviais, podendo melhorar a qualidade do ar e da água e diminuir a sobrecarga do escoamento. No entanto, esse sistema não pode resolver o problema isoladamente, havendo a necessidade de ser combinado com outras medidas de redução de escoamento. A composição da estrutura do telhado verde interfere menos na qualidade do armazenamento quando comparada ao clima e estação do ano. As regiões de clima quente são as mais indicadas para a incorporação do telhado verde. Climas tropicais, predominantes no território brasileiro, são favoráveis para a eficácia do telhado verde. Nesses climas, principalmente devido às altas temperaturas, o processo de evapotranspiração é dinâmico, contribuindo para a não saturação do solo.

Os telhados verdes intensivos possuem substrato espesso e a aparência de um jardim convencional, com plantas de maior porte. Já os telhados verdes extensivos possuem substrato mais fino, com vegetação composta geralmente por gramíneas. O projeto básico de telhado verde extensivo é de menor complexidade de instalação e com registros de implementação em diversas regiões ao redor do mundo. A seleção do tipo de telhado verde a ser implementado deve levar em consideração, além de outros fatores, a estrutura da edificação, os custos de implantação e manutenção.

Os projetos de edificações, bem como o planejamento urbano devem incorporar o conceito de sustentabilidade com vistas à melhoria das condições de infiltração, temperatura e escoamento em centros urbanos.

\section{REFERÊNCIAS}

ARNOLD JR, C. L.; GIBBONS, C. James. Impervious surface coverage: the emergence of a key environmental indicator. Journal of the American planning Association, v. 62, n. 2, p. 243-258, 1996. DOl: https:// doi.org/10.1080/01944369608975688

BAPTISTA, M.; NASCIMENTO, N.; BARRAUD, S. Técnicas Compensatórias em Drenagem Urbana, Porto Alegre: Associação Brasileira de Recursos Hídricos, 2015. 2a reimpressão da $2^{\mathrm{a}}$ edição, $318 \mathrm{p}$.

BENGTSSON, L. Peak flows from thin sedum-moss roof. Hydrology Research, v. 36, n. 3, p. 269-280, 2005 DOI: https://doi.org/10.2166/nh.2005.0020

BENGTSSON, L.; GRAHN, L.; OLSSON, J. Hydrological function of a thin extensive green roof in southern Sweden. Hydrology Research, v. 36, n. 3, p. 259-268, 2005. DOI: https://doi.org/10.2166/nh.2005.0019 
BERNDTSSON, J. C.; BENGTSSON, L.; JINNO, K.. Runoff water quality from intensive and extensive vegetated roofs. Ecological engineering, v. 35, n. 3, p. 369-380, 2009. DOI: https://doi.org/10.1016/j. ecoleng.2008.09.020

CARTER, T. L.; RASMUSSEN, T. C. Hydrologic Behavior of Vegetated Roofs 1. JAWRA Journal of the American Water Resources Association, v. 42, n. 5, p. 1261-1274, 2006.

CASTLETON, H. F. et al. Green roofs; building energy savings and the potential for retrofit. Energy and buildings, v. 42, n. 10, p. 1582-1591, 2010. DOI: https://doi. org/10.1016/j.ecoleng.2008.09.020

CANOAS-RS (Município). Lei n 5.840, de 27 de maio de 2014. Dispõe sobre a criação de telhados verdes e seus critérios técnicos especificados nesta lei e dá outras providências. 2014.

COSTANZA, R. et al. The value of the world's ecosystem services and natural capital. Nature, v. 387, n. 6630, p. 253, 1997.

CEMBRANO, G. et al. Optimal control of urban drainage systems. A case study. Control engineering practice, v. 12, n. 1, p. 1-9, 2004.

CHARLESWORTH, S. et al. A comparative study of heavy metal concentration and distribution in deposited street dusts in a large and a small urban area: Birmingham and Coventry, West Midlands, UK. Environment International, v. 29, n. 5, p. 563-573, 2003. DA COSTA RANGEL, Ana Celecina Lucena; ARANHA, Kaline Cunha; DA SILVA, Maria Cristina Basílio Crispim. Os telhados verdes nas políticas ambientais como medida indutora para a sustentabilidade. Desenvolvimento e Meio Ambiente, v. 35, 2015.

DENARDO, J. C. et al. Stormwater mitigation and surface temperature reduction by green roofs. Transactions of the $A S A E$, v. 48, n. 4, p. 1491-1496, 2005. DOI: $10.13031 / 2013.19181$

DIETZ, M. E. Low impact development practices: A review of current research and recommendations for future directions. Water, air, and soil pollution, v. 186, n. 1-4, p. 351-363, 2007. DOI: https://link.springer.com/ article/10.1007/s11270-007-9484-z

DHALLA, S.; ZIMMER, C. Low Impact Development Stormwater Management Planning and Design Guide. Toronto and Toronto and Region Conservation Authority: Toronto, ON, Canada, v. 300, 2010.

DUNNETT, N.; KINGSBURY, N. Planting options for extensive and semi-extensive green roofs. Greening Rooftops for Sustainable Communities, Portland, OR,
2004.

EKSI, M.; ROWE, D. B.; WICHMAN, I. S.; ANDRESEN, J. A. Effect of substrate depth, vegetation type, and season on green roof thermal properties. Energy and Buildings, v. 145, p. 174-187, 2017. DOI: https://doi.org/10.1016/j.enbuild.2017.04.017

ELLIS, J. B. et al. Multicriteria decision approaches to support sustainable drainage options for the treatment of highway and urban runoff. Science of the total Environment, v. 334, p. 251-260, 2004. DOI: https://doi. org/10.1016/j.scitotenv.2004.04.066

FERGUSON, B. K. Introduction to stormwater: concept, purpose, design. John Wiley \& Sons, 1998.

GAFFIN, S. et al. Quantifying evaporative cooling from green roofs and comparison to other land surfaces. In: Fourth Annual Greening Rooftops for Sustainable Communities Conference, Awards and Trade Show. 2006. p. 11-12.

GARRIDO NETO, P. de S. Telhados verdes como técnica compensatória em drenagem urbana na cidade do Rio de Janeiro: Estudo experimental e avaliação de sua adoção na bacia do rio Joana a partir do uso de modelagem matemática. Instituto Alberto Luiz Coimbra de Pós-Graduação e Pesquisa de Engenharia (COPPE), Universidade Federal do Rio de Janeiro. Rio de JaneiroRJ, 321p, 2016.

GETTER, K. L.; ROWE, D. Bradley; ANDRESEN, Jeffrey A. Quantifying the effect of slope on extensive green roof stormwater retention. Ecological engineering, v. 31, n. 4, p. 225-231, 2007.DOI: https://doi.org/10.1016/j. ecoleng.2007.06.004

GETTER, K. L.; ROWE, D. B.; ROBERTSON, G. P.; CREGG, B. M.; ANDRESEN, J. A. Carbon sequestration potential of extensive green roofs. Environmental science $\&$ technology, v. 43, n. 19, p. 7564-7570, 2009. DOI: https:// doi.org/10.1021/es901539x

GOIANIA-GO (Município), Lei Complementar № 235, de 28 de Dezembro De 2012. Institui o PROGRAMA IPTU VERDE no Município de Goiânia. 2012.

GUARULHOS-SP (Município). Lei n 6.793, de 28 de dezembro de 2010. Dispõe sobre o lançamento, arrecadação e fiscalização do imposto sobre a propriedade predial e territorial urbana - IPTU e dá outras providências. 2010.

GUARULHOS-SP (Município). LEI No 7.031, DE 17 DE ABRIL DE 2012. Dispõe sobre a instalação do "telhado verde" nos locais que especifica, e dá outras providências. 2012.

JOÃO PESSOA-PB (Município). LEI No 10.047 DE 09 DE 
JULHO DE 2013. Dispõe sobre a obrigatoriedade da instalação do "Telhado Verde" nos locais que especifica, e dá outras providências. 2013.

JONES, P.; MACDONALD, N. Making space for unruly water: Sustainable drainage systems and the disciplining of surface runoff. Geoforum, v. 38, n. 3, p. 534-544, 2007. DOI: https://doi.org/10.1016/j. geoforum.2006.10.005

KÖHLER, M. et al. Green roofs in temperate climates and in the hot-humid tropics-far beyond the aesthetics. Environmental management and health, v. 13, n. 4, p. 382-391, 2002.

KRUPKA, Bernd. Dachbegrünung: Pflanzen-und Vegetationsanwendung an Bauwerken. Ulmer, 1992.

LEITMANN, J. Sustaining cities: environmental planning and management in urban design. New York: McGraw-Hill, 1999.

MENTENS, J.; RAES, D.; HERMY, M. Green roofs as a tool for solving the rainwater runoff problem in the urbanized 21st century?. Landscape and urban planning, v. 77, n. 3, p. 217-226, 2006. DOI: https://doi.org/10.1016/j. landurbplan.2005.02.010

MIGUEZ, M.G.; MASCARENHAS, F.C.B.; MAGALHÃES, L.P.C. Multifunctional Landscapes for Urban Flood Control in Developing Countries. International Journal of Sustainable Development and Planning, v. 2, n. 2, p. 153-166, 2007.

NIACHOU, A. et al. Analysis of the green roof thermal properties and investigation of its energy performance. Energy and buildings, v. 33, n. 7, p. 719-729, 2001. DOI: https://doi.org/10.1016/S0378-7788(01)00062-7

OBERNDORFER, E. et al. Green roofs as urban ecosystems: ecological structures, functions, and services. BioScience, v. 57, n. 10, p. 823-833, 2007. DOI: https:// doi.org/10.1641/B571005

OKE, T. R.; CLEUGH, H. A. Urban heat storage derived as energy balance residuals. Boundary-Layer Meteorology, v. 39, n. 3, p. 233-245, 1987. DOI: https:// link.springer.com/article/10.1007/BF00116120

PAUL, M. J.; MEYER, J. L. Streams in the urban landscape. Annual review of Ecology and Systematics, v. 32, n. 1, p. 333-365, 2001.

PICKETT, S. TA et al. Urban ecological systems: linking terrestrial ecological, physical, and socioeconomic components of metropolitan areas. Annual review of ecology and systematics, v. 32, n. 1, p. 127-157, 2001.

POLETO, C.; SILVEIRA, A. L. L.; CARDOSO, A.R.; GOLDENFUM, J;A; DORNELLES, F.; TASSI, R.; MOURA, P. M. Águas Urbanas: Volume 1. Porto Alegre: ABRH, 2015.
$142 \mathrm{p}$.

RECIFE-PE (Município). Lei no 18.112, de 12 de janeiro de 2015. Dispõe sobre a melhoria da qualidade ambiental das edificações por meio da obrigatoriedade de instalação do "telhado verde", e construção de reservatórios de acúmulo ou de retardo do escoamento das águas pluviais para a rede de drenagem e dá outras providências. 2015.

RIO DE JANEIRO. Lei n 6.349, de 30 de novembro de 2012. Dispõe sobre a obrigatoriedade da instalação do "telhado verde" nos locais que especifica e dá outras providências. 2012.

ROWE, D. B. Green roofs as a means of pollution abatement. Environmental pollution, v. 159, n. 8-9, p. 2100-2110, 2011. DOI: https://doi.org/10.1016/j. envpol.2010.10.029

SALVADOR-BA， DECRETO No 29.100 DE 06 DE NOVEMBRO DE 2017. Regulamenta o art. $5^{\circ}$ da Lei no 8.474, de 02 de outubro de 2013, e institui o Programa de Certificação Sustentável "IPTU VERDE" em edificações no Município de Salvador, que estabelece benefícios fiscais aos participantes do programa, assim como o art. $5^{\circ}$ da Lei 8.723 de 22 de dezembro de 2014 e dá outras providências. 2017.

SANTA CATARINA. Lei no 14.243, de 11 de dezembro de 2007. Dispõe sobre a implementação de sistemas de naturação através da criação de telhados verdes em espaços urbanos de Santa Catarina. 2007.

SANTAMOURIS, M. et al. Investigating and analyzing the energy and environmental performance of an experimental green roof system installed in a nursery school building in Athens, Greece. Energy, v. 32, n. 9, p. 1781-1788, 2007. DOI: https://doi.org/10.1016/j. energy.2006.11.011

SANTOS-SP (Município). LEI COMPLEMENTAR No 913 DE 21 DE DEZEMBRO DE 2015. Concede Incentivo Fiscal à Implantação de "Coberturas Verdes" nos Edifícios do Município, e dá outras Providências. 2015.

SÃO PAULO-SP (Município). Decreto no 16.277, de 05 de outubro de 2015. Dispõe sobre a obrigatoriedade da instalação do "Telhado Verde" em locais específicos. 2015.

SHAFIQUE, Muhammad; KIM, Reeho; RAFIQ, Muhammad. Green roof benefits, opportunities and challenges-A review. Renewable and Sustainable Energy Reviews, v. 90, p. 757-773, 2018. DOI: https:// doi.org/10.1016/j.rser.2018.04.006

TEEMUSK, A.; MANDER, Ü. Greenroof potential to reduce temperature fluctuations of a roof membrane: a 
case study from Estonia. Building and Environment, v. 44, n. 3, p. 643-650, 2009. DOI: https://doi.org/10.1016/j. buildenv.2008.05.011

THOMSON, W. J.; SORVIG, K. Sustainable Landscape Construction. A guide to green building outdoor. 2008.

TSANG, S. W.; JIM, C. Y. Theoretical evaluation of thermal and energy performance of tropical green roofs. Energy, v. 36, n. 5, p. 3590-3598, 2011. DOI: https://doi. org/10.1016/j.energy.2011.03.072

TUCCl, Carlos E. M. Águas urbanas. Estud. av., São Paulo, v. 22, n. 63, p. 97-112, 2008.

VANWOERT, N. D. et al. Green roof stormwater retention. Journal of environmental quality, v. 34, n. 3, p. 1036-1044, 2005.

VECCHIA, F. Cobertura Verde Leve (CVL): ensaio experimental. In: ENCONTRO NACIONAL DE CONFORTO NO AMBIENTE CONSTRUÍDO, 6.,Maceió, 2005, Maceió. Anais. Maceió: ANTAC, 2005.

VILLARREAL, E. L.; BENGTSSON, L. Response of a Sedum green-roof to individual rain events. Ecological Engineering, v. 25, n. 1, p. 1-7, 2005. DOI: https://doi.org/10.1016/j.ecoleng.2004.11.008

YANG, J.; YU, Q.; GONG, P. Quantifying Air Pollution Removal by Green Roofs in Chicago. Atmospheric Environment, v. 42, n. 31, p. 7266-7273, oct. 2008 DOI: https://doi.org/10.1016/j.atmosenv.2008.07.003

WILLEMS, P. et al. Climate change impact assessment on urban rainfall extremes and urban drainage: Methods and shortcomings. Atmospheric research, v. 103, p. 106-118, 2012. DOI: https://doi.org/10.1016/j. atmosres.2011.04.003

WHITE, R. R. Building the ecological city. Elsevier, 2002. WHITTINGHILL, Leigh J.; ROWE, D. Bradley. The role of green roof technology in urban agriculture. Renewable Agriculture and Food Systems, v. 27, n. 4, p. 314-322, 2012. DOI: https://doi.org/10.1017/S174217051100038X WONG, N. H. et al. Investigation of thermal benefits of rooftop garden in the tropical environment. Building and environment, v. 38, n. 2, p. 261-270, 2003. DOI: https://doi.org/10.1016/S0360-1323(02)00066-5

\section{AUTORES}

ORCID: https://orcid.org/0000-0002-9163-0731

ETHEL GERALDO CANABRAVA NETO | UFMS | Endereço para correspondência: Av. Costa e Silva, s/n $\mid$ Cidade Universitária |79070-900 | Campo Grande|MS|Brasil. | e-mail: ethelcanabrava1@gmail.com

ORCID: https://orcid.org/0000-0003-3821-3776

ALESKA KAUFMANN ALMEIDA, M.Sc. | UFMS | Endereço para correspondência: Av. Costa e Silva, s/n $\mid$ Cidade Universitária |79070-900 | Campo Grande|MS|Brasil.| e-mail: aleska.kaufmann@gmail.com

ORCID: https://orcid.org/0000-0001-8871-3926

IZABEL RODRIGUES LEITE, M.Sc. | UFMS | Endereço para correspondência: Av. Costa e Silva, s/n $\mid$ Cidade Universitária |79070-900 | Campo Grande|MS|Brasil.| e-mail: izabelleite93@hotmail.com

ORCID: https://orcid.org/0000-0003-0962-7777

JOSÉ ANTONIO GUARIENTI | UFMS | Endereço para correspondência: Av. Costa e Silva, s/no | Cidade Universitária |79070-900 | Campo Grande|MS|Brasil.| e-mail: jose.guarienti@gmail.com

ORCID: https://orcid.org/0000-0002-8609-2991

ISABEL KAUFMANN DE ALMEIDA, Dra. | UFMS | Endereço para correspondência: Av. Costa e Silva, s/n $\mid$ Cidade Universitária |79070-900 | Campo Grande|MS|Brasil.| e-mail: isabel.almeida@ufms.br

\section{COMO CITAR ESTE ARTIGO}

CANABRAVA NETO, Ethel Geraldo; ALMEIDA, Aleska Kaufmann; LEITE, Izabel Rodrigues; GUARIENTI, José Antonio; ALMEIDA, Isabel Kaufmann de. Telhado Verde: Alternativa Sustentável Para A Drenagem Do Escoamento Superficial. MIX Sustentável, [S.I.], v. 7, n. 2, p. 125-136, abr. 2021. ISSN 24473073. Disponível em:<http://www.nexos.ufsc.br/index.php/mixsustentavel>. Acesso em: dia mês. ano. doi:https://doi. org/10.29183/2447-3073.MIX2021.v7.n2.125-136.

DATA DE ENVIO: 20/09/2020

DATA DE ACEITE: $17 / 01 / 2021$ 
